\title{
Tuberculin Skin Test and CD4+/CD8+ T Cell Counts in Adults Infected with the Human Immunodeficiency Virus in Medellín, Colombia
}

\author{
JI Rodríguez, M Arias, SC París, MP Arbeláez*, J Betancur**, LF García/+
}

Laboratorio Central de Investigaciones *Facultad Nacional de Salud Pública **Departamento de Medicina
Interna, Universidad de Antioquia, Medellín, Colombia

To evaluate the effect of BCG vaccination and T lymphocyte subpopulations on the reactivity to the tuberculin skin test, 113 asymtomatic HIV+ individuals were tuberculin tested by intradermal injection of 5TU of purified protein derivative and the levels of circulating lymphocyte (CD3, CD4 and CD8) subpopulations determined by indirect immunofluorescence. Ninety-two percent of the subjects included in the study were males. The mean age of the group was 32.1 \pm 7.4 years. Sixty-two percent presented a $B C G$ scar. However, only $22 \%$ exhibited positive tuberculin reactions $(\geq 5 \mathrm{~mm})$ irrespective of the presence of the BCG scar. Tuberculin positive individuals exhibited higher $C D 4+$ cell counts $(p=0.004)$ and $C D 4+/ C D 8+$ ratios $(p=0.006)$ than tuberculin negative $(<5 \mathrm{~mm}) H I V+$ individuals. The number of individuals with positive tuberculin reactions was significantly higher in subjects with more than 500 $C D 4+$ lymphocytes $/ \mu l(p=0.02)$ or $C D 4+/ C D 8+$ ratios $\geq 1.12(p=0.002)$.

These results suggest that a prior $B C G$ vaccination does not influence the reactivity to the tuberculin skin test in HIV+ asymptomatic individuals and that the number of CD4+ lymphocytes and the CD4+/ $C D 8+$ ratio positively correlate with the tuberculin reactivity.

Key words: HIV - tuberculin - BCG vaccination - CD4 - CD8

Infection with the human immunodeficiency virus (HIV) is an important risk factor for progression from asymptomatic tuberculous infection to active disease (Rieder et al. 1989, Selwyn et al. 1989, Raviglione et al. 1992, Barnes et al. 1993). Tuberculin skin test is currently the only practical method available to identify latent Mycobacterium tuberculosis infections (CDC 1990a, Huebner et al. 1993). The role of $\mathrm{T}$ lymphocytes in delayed type hypersensitivity (DTH) responses, such as the tuberculin skin test, has been extensively demonstrated (Orme et al. 1993). Among T cells, the CD4+ subpopulation is important for the memory response to purified protein derivative (PPD) after exposure to natural mycobacterial infections, disease or secondary to vaccination with BCG (Huebner et al. 1993, Orme et al. 1993). HIV infection leads to CD4+ cell destruction and hence to anergy of most of the T celldependent DTH reactions, including tuberculin skin

\footnotetext{
This work was supported by the Fundación para la Promoción de la Investigación y la Tecnología (Santafé de Bogotá, Colombia) and the Dirección Seccional de Salud de Antioquia (Medellín, Colombia).

${ }^{+}$Corresponding author. Fax: +57-4-263.3509. E-mail: lfgarcia@quimbaya.udea.edu.co

Received 2 July 1996

Accepted 13 November 1996
}

test (Sears et al. 1987, CDC 1990a, Graham et al. 1992); therefore, this tool needs to be re-evaluated since a negative tuberculin test might be due to a true lack of exposure to mycobacteria or to an incapacity to respond to the challenge with mycobacterial antigens. The CD8+ $\mathrm{T}$ cell subpopulation may also have a regulatory role, so that the $\mathrm{CD} 4+/ \mathrm{CD} 8+$ ratio could represent not only the proportion of both cell types in the circulation but their functional balance in the immune response to mycobacteria (Orme et al. 1993).

The aim of this report was to study the influence of BCG vaccination, in a country with high coverage of BCG vaccination, and T cell counts on tuberculin reactivity in HIV+ subjects. For this purpose we determined the prevalence rates of tuberculin positivity, following the Centers for Disease Control (CDC) recommendation (CDC 1991), among BCG vaccinated- and non-vaccinated asymptomatic HIV seropositive individuals and correlated these findings with the counts of circulating CD4+ and CD8+ T lymphocytes.

\section{MATERIALS AND METHODS}

Subjects studied - From June 1993 to June 1994, 113 asymptomatic HIV-seropositive adults were recruited from the programs for control of HIV infection of the Dirección Seccional de Salud de Antioquia (DSSA), Instituto de Seguros Sociales 
(I.S.S.), Instituto Metropolitano de Salud de Medellín (Metrosalud), Medellín, Colombia. All the patients were in a follow-up program looking for the progression of AIDS-associated tuberculosis. An informed consent was obtained from each participant and demographical and clinical information, specifically the history of clinical tuberculosis, BCG vaccination (determined by the presence of BCG scar), was collected. Tuberculin skin test was done by injecting intradermally $0.1 \mathrm{ml}$ of PPD (5 TU per test, Connaugh Laboratories, North York, Ontario, Canada) and the mean diameter of induration was determined after $72 \mathrm{hr}$. A positive PPD test was considered for a mean induration diameter equal or greater than $5 \mathrm{~mm}$ in $\mathrm{HIV}+$ individuals (CDC 1991).

T cell subsets counts - CD3+, CD4+ and CD8+ $\mathrm{T}$ cell counts were determined by indirect immunofluorescence. Briefly, $15 \mathrm{ml}$ of venous blood were drawn in Vacutainer tubes containing EDTA (Becton Dickinson, Rutherford, New Jersey, USA). An aliquot of $5 \mu \mathrm{l}$ of whole blood was smeared, dried by air and stained with Wright's. The leukocyte differential count was determined by microscopy. Another aliquot was used to obtain the absolute count of leukocytes in hemocytometer.

Blood samples were centrifuged at $1000 \mathrm{x} \mathrm{g}$ for $15 \mathrm{~min}$ at room temperature. The buffy coat was collected and resuspended in PBS, $0.15 \mathrm{M}$, $\mathrm{pH}$ 7.2. The leukocytes were layered over $3 \mathrm{ml}$ of Histopaque 1.077 (Sigma Chemical Co., St. Louis, Mo, USA) and centrifuged at $700 \mathrm{x} g$ for $10 \mathrm{~min}$ at room temperature. The mononuclear cells were recovered and washed twice with cold PBS containing $0.1 \%$ sodium azide (PBS-azide). Viability, as measured by trypan blue, was always higher than $95 \%$. Cells were resuspended at $1 \times 10^{7} / \mathrm{ml}$ in cold PBS-azide. Aliquots of $100 \mu \mathrm{l}$ of the cell suspension were incubated with $5 \mu \mathrm{l}$ of either antiCD3, anti-CD4 or anti-CD8 monoclonal antibodies (Coulter, Hialleah, Fl, USA ) for $30 \mathrm{~min}$ at $4^{\circ} \mathrm{C}$. The cells were washed with cold PBS-azide at $200 \mathrm{x} \mathrm{g}$ for $10 \mathrm{~min}$ at $4^{\circ} \mathrm{C}$, resuspended in $50 \mu \mathrm{l}$ of cold PBS-azide plus $5 \mu \mathrm{l}$ of the second antibody conjugated to fluorescein isotiocyanate (GAMFITC, Coulter) and $1 \mu \mathrm{l}$ of $1 \mu \mathrm{g} / \mathrm{ml}$ ethidium bromide (Sigma) and incubated for $30 \mathrm{~min}$ more at $4^{\circ} \mathrm{C}$. Finally, the cells were washed once with cold PBS-azide and resuspended in PBS containing 30\% glycerin and $10 \%$ formaldehyde for microscopic examination. A $10 \mu \mathrm{l}$ aliquot was counted for each marker in an epifluorescence microscopy (Leitz, Oberkochen, Germany), excluding dead cells stained by ethidium bromide.

Statistical analysis - Statistical analyses were performed using the Statgraphics plus V. 6.0 software. Comparisons of proportions were done by
Chi Square and Fisher Exact Test. Comparisons of means were made by non-paired Student's t test. A p $\leq 0.05$ was considered statistically significant.

\section{RESULTS}

One hundred and thirteen HIV-seropositive asymptomatic individuals were studied. Demographic data are shown in Table I. In this group, $92 \%$ were male. The mean age was $32.1 \pm 7.4$ years and the age when the serologic diagnosis was done was $31.0 \pm 9.7$ years. Only $8 \%$ of the patients had received antiretroviral treatment (AZT or DDI) at the moment of recruitment. Nine individuals were excluded for further analysis because there was no complete information on the lymphocyte subpopulations.

TABLE I

General data on HIV-positive individuals studied

\begin{tabular}{ccrr}
\hline & & $\mathrm{n}$ & $\%$ \\
\hline Sex & Males & 104 & \\
& Females & 9 & 82 \\
\multicolumn{2}{c}{ Age (years) } & & \\
$15-19$ & 1 & 13 \\
$20-24$ & 14 & 26 \\
$25-29$ & 29 & 23 \\
$30-34$ & 25 & 20 \\
$35-39$ & 22 & 17 \\
& & 19 &
\end{tabular}

Mean \pm sd $32.1 \pm 7.4$

Age at diagnosis (years)

$\begin{array}{lrr}15-19 & 1 & 1 \\ 20-24 & 17 & 19 \\ 25-29 & 28 & 31 \\ 30-34 & 24 & 27 \\ 35-39 & 5 & 6 \\ \geq 40 & 14 & 16\end{array}$

Mean \pm sd $\quad 31.0 \pm 9.7$

AZT or DDI treatment

\begin{tabular}{lrr}
+ & 9 & 8 \\
- & 101 & 89 \\
Not known & 3 & 3 \\
\hline
\end{tabular}

In 104 HIV+ individuals, $64(62 \%)$ had the BCG scar (Table II). The percentage of HIV+ individuals with positive tuberculin skin test $(\geq 5 \mathrm{~mm})$ was exactly the same $(22 \%)$ in subjects with or without BCG scar.

The total leukocyte, the differential leukocyte (data not shown) and lymphocyte counts, found in the HIV+ subjects studied were within the normal ranges for general population (Yamagami \& Lum 1992) (Table III). The mean of leukocyte counts was $7636 \pm 2893$. The total CD3+ cell counts were $1797 \pm 976$, with $865 \pm 668 \mathrm{CD} 4+\mathrm{T}$-cells and 
$1264 \pm 891 \mathrm{CD} 8+\mathrm{T}$ cell. Accordingly, the CD4+/ CD8+ ratio was $0.81 \pm 1.03$.

When the lymphocyte counts where compared accordingly to the tuberculin reactivity (Table IV), the CD3+ and CD8+ counts showed no differences between tuberculin-positive and negative HIV+ subjects. However, the CD4+ (764 versus 1254;

TABLE II

Tuberculin skin test and BCG vaccination in the HIVpositive individuals studied

\begin{tabular}{ccrr}
\hline & \multicolumn{2}{c}{ BCG Vaccination } & \\
\cline { 2 - 3 } $\begin{array}{c}\text { Tuberculin } \\
\text { skin test }\end{array}$ & $\begin{array}{c}+ \\
\mathrm{n}(\%)\end{array}$ & $\mathrm{n}(\%)$ & $\begin{array}{r}\text { Total } \\
\mathrm{n}(\%)\end{array}$ \\
\hline$\geq 5 \mathrm{~mm}$ & $14(22)$ & $9(22)$ & $23(22)$ \\
$0-4 \mathrm{~mm}$ & $50(78)$ & $31(78)$ & $81(78)$ \\
\hline Total & $64(62)$ & $40(38)$ & $104(100)$ \\
\hline
\end{tabular}

$a$ : BCG vaccination was considered positive when scar was present. $\mathrm{p}=0.004)$ and the $\mathrm{CD} 4+/ \mathrm{CD} 8+$ ratios $(0.65$ versus $1.4 ; \mathrm{p}=0.006$ ) were significantly lower for the tuberculin negative compared to tuberculin positive HIV+ subjects. These findings were further supported by the fact that while one third of the subjects with BCG scar and more than $500 \mathrm{CD} 4+$ lymphocytes per $\mu 1$ were tuberculin positive, only $4 \%$ of those patients with CD4 counts below 500 cells $/ \mu 1$ had a positive tuberculin skin test (Table V) $(\mathrm{p}=0.02)$. These differences remained in BCG-non vaccinated individuals $(\mathrm{p}=0.03)$ suggesting that prior vaccination with BCG had no effect on the tuberculin reactivity in HIV-positive subjects. A similar situation was observed for the CD4+/CD8+ ratios (Table VI). While $64 \%$ of the BCG scar positive individuals with ratios $\geq 1.12$ had a positive tuberculin skin test, only $14 \%$ of those with $\mathrm{CD} 4+/ \mathrm{CD} 8+$ ratio $<1.12$ showed a positive tuberculin skin test $(\mathrm{p}=0.002)$. In the $\mathrm{BCG}$ non-vaccinated subjects a similar situation was observed $(\mathrm{p}=0.03)$.

TABLE III

Leukocyte and T lymphocyte counts in HIV-positive individuals

\begin{tabular}{cccccr}
\hline $\begin{array}{c}\text { Total } \\
\text { leukocytes }^{a}\end{array}$ & $\begin{array}{c}\text { Total } \\
\text { lymphocytes }\end{array}$ & $\begin{array}{c}\text { CD3+ } \\
\text { T cells }\end{array}$ & $\begin{array}{c}\text { CD4+ } \\
\text { T cells }\end{array}$ & $\begin{array}{c}\text { CD8+ } \\
\text { T cells }\end{array}$ & $\begin{array}{c}\text { CD4+/CD8+ } \\
\text { ratio }\end{array}$ \\
\hline 7636 & 2679 & 1797 & 865 & 1264 & 0.81 \\
\pm 2893 & \pm 1337 & \pm 976 & \pm 668 & \pm 891 & \pm 1.03 \\
\hline
\end{tabular}

a: cells/ $\mu 1 \pm$ Standard deviation

TABLE IV

Leukocytes, T lymphocyte subpopulation counts $( \pm \mathrm{SD}), \mathrm{CD} 4+/ \mathrm{CD} 8+$ ratios and tuberculin reactivity in HIV-positive individuals

\begin{tabular}{lccc}
\hline \multirow{2}{*}{$\begin{array}{l}\text { Lymphocytes } \\
\text { (subpopulation) }\end{array}$} & \multicolumn{2}{c}{ Tuberculin reactivity } & $\mathrm{p}={ }^{a}$ \\
\cline { 2 - 4 } & $<5 \mathrm{~mm}$ & $23 \mathrm{~mm}$ & \\
$\mathrm{n}=$ & 81 & $2884 \pm 1090$ & n.s. \\
Total lymphocytes & $2614 \pm 1412$ & $2100 \pm 915$ & n.s. \\
CD 3+ & $1711 \pm 989$ & $1254 \pm 599$ & 0.004 \\
CD 4+ & $764 \pm 656$ & $1247 \pm 698$ & n.s. \\
CD 8+ & $1274 \pm 952$ & $1.40 \pm 1.95$ & 0.006 \\
CD4+/CD8+ ratio & $0.65 \pm 0.5$ & \\
\hline
\end{tabular}

a: Student's t test; n.s.: not significant

TABLE V

Tuberculin reactivity, BCG vaccination and CD4+ lymphocyte counts in HIV-positive individuals

\begin{tabular}{|c|c|c|c|c|}
\hline \multirow{3}{*}{$\begin{array}{l}\text { Tuberculin } \\
\text { reactivity }\end{array}$} & \multicolumn{2}{|c|}{ CD4+ lymphocyte } & \multicolumn{2}{|c|}{ Counts } \\
\hline & \multicolumn{2}{|c|}{ BCG vaccinated $^{a}$} & \multicolumn{2}{|c|}{ BCG non-vaccinated ${ }^{b}$} \\
\hline & $\geq 500 / \mu 1$ & $<500 / \mu 1$ & $\geq 500 / \mu 1$ & $<500 / \mu 1$ \\
\hline$\geq 5 \mathrm{~mm}$ & $13(33)^{c}$ & $1(4)$ & $8(28)$ & $0(0)$ \\
\hline $0-4 \mathrm{~mm}$ & $26(67)$ & $22(96)$ & $21(72)$ & $8(100)$ \\
\hline Total & $39(63)$ & $23(37)$ & $29(78)$ & $8(22)$ \\
\hline
\end{tabular}

$a$ : BCG vaccinated, $\mathrm{p}=0.02$ (Yates' corrected chi-square); $b$ : BCG non-vaccinated, $\mathrm{p}=0.03$ (Yates' corrected chisquare); $c: \mathrm{n}(\%)$; vaccinated $v s$ non-vaccinated: not significant 
TABLE VI

Tuberculin reactivity, CD4+/CD8+ ratios and BCG vaccination in HIV-positive individuals

\begin{tabular}{|c|c|c|c|c|}
\hline \multirow{3}{*}{$\begin{array}{l}\text { Tuberculin } \\
\text { reactivity }\end{array}$} & \multicolumn{4}{|c|}{ CD4+/CD8+ratios } \\
\hline & \multicolumn{2}{|c|}{ BCG vaccinated $^{a}$} & \multicolumn{2}{|c|}{ BCG non-vaccinated ${ }^{b}$} \\
\hline & $\geq 1.12$ & $<1.12$ & $\geq 1.12$ & $<1.12$ \\
\hline$\geq 5 \mathrm{~mm}$ & $7(64)^{c}$ & $7(14)$ & $5(56)$ & $4(14)$ \\
\hline $0-4 \mathrm{~mm}$ & $4(36)$ & $42(86)$ & $4(44)$ & $25(86)$ \\
\hline Total & $11(18)$ & $49(82)$ & $9(23)$ & $29(77)$ \\
\hline
\end{tabular}

$a$ : BCG vaccinated, $\mathrm{p}=0.002$ (Yates' corrected chi square); $b$ : BCG non-vaccinated, $\mathrm{p}=0.03$ (Yates' corrected chi square); $c$ : n (\%); vaccinated vs non-vaccinated: not significant

\section{DISCUSSION}

To determine whether tuberculin skin test can identify individuals with latent mycobacterial infections in HIV+ individuals, despite the compromise of their immune system, 113 asymptomatic $\mathrm{HIV}+$ individuals were tuberculin skin tested, the presence of a BCG scar observed, and the number of circulating $\mathrm{CD} 4+$ and $\mathrm{CD} 8+\mathrm{T}$ cells were counted.

Vaccination with BCG does not seem to have any effect on the positivity of the tuberculin skin test in asymptomatic HIV+ subjects. A similar percentage of positive reactors to PPD were found irrespectively of the presence of the BCG scar, indicating that the immune defects secondary to the HIV infection are present before clinical AIDS is manifested. A high percentage of tuberculin negative tests were observed despite the cut off point of 5-mm recommended by the CDC (1991). These findings are in agreement with those from other authors (Sears et al. 1987, Graham et al. 1992, Alzate et al. 1993). In Uganda, a follow-up study of HIV infection in postpartum women (CDC $1990 b)$, provided the opportunity to study the tuberculin reactivity of apparently healthy women of known HIV serological status. Results were available for 94 women (33 HIV- and $61 \mathrm{HIV+}$ ). Among the HIV-women, 25 (82\%) had tuberculin skin test greater than $3 \mathrm{~mm}$ (median diameter $10.6 \mathrm{~mm})$, whereas 29 (49\%) seropositive women had a skin test equal or greater than $3 \mathrm{~mm}$ (median size $7.5 \mathrm{~mm}$; p<0.05). Graham et al. (1992), in a group of HIV+ intravenous drug users, using the CDC definition of an induration of $5 \mathrm{~mm}$ or greater in diameter (CDC 1991), found that this group was substantially less likely to be tuberculin positive than HIV-1 seronegatives. The mean diameter of the induration in the HIV+ group was $2.6 \mathrm{~mm}$ versus $5.4 \mathrm{~mm}$ in the seronegative group.

In our study we observed a positive correlation between tuberculin positivity and CD4+ lymphocyte counts. The proportion of tuberculin positive reactors was ten times lower in individuals with less than $500 \mathrm{CD} 4+/ \mu 1$, compared to those with $\geq 500 \mathrm{CD} 4+/ \mu \mathrm{l}$. For some authors (Sears et al. 1987, Markowitz et al. 1993), anergy to skin tests (including mumps and candidin antigens) could explain these differences. Tuberculin unresponsiveness was substantially higher in the HIV-1 seropositive group and increased as the CD4+ lymphocyte count diminished (Graham et al. 1992, Markowitz et al. 1993). However, the anergy test could not absolutely sustain this observation since the prevalence of $M$. tuberculosis infection (Huebner et al. 1993) could modify the rate of tuberculin positivity. Furthermore, due to the specificity of the immune response to lipoarabinomannan and other mycobacterial antigens (Bothamley et al. 1992) and because the killing of CD4+ lymphocytes by HIV is a random phenomenon, anergy is not necessarily a global fact. Additionally, there are no formal studies evaluating the validity of the anergy panels (Pesanti 1994). All this evidence suggest that the CDC-recommended definition (CDC 1991) could lead to missclassification of TB infection in $\mathrm{HIV}+$ individuals in countries with high incidence of mycobacterial infections, since the alterations inherent to HIV infection could render negative and otherwise positive tuberculin skin test very early during the HIV infections (Markowitz et al. 1993).

It has been shown that the presence of BCG scar, indicative of prior vaccination with $M$. bovis $\mathrm{BCG}$, correlates with the reactivity to tuberculin in normal individuals (Larsson et al. 1992), specially in countries like Colombia, in which BCG vaccination is compulsory in newborns, with coverages greater than $80 \%$. However, in the HIV+ individuals studied herein the rate of tuberculin positivity was similar regardless the BCG-vaccination status. An important finding from the Uganda study (CDC 1990b) was that previous vaccination with BCG appears to maintain tuberculin reactivity at higher levels than the "natural" mycobacterial infection. In these cases BCG vaccination complicates the interpretation of skin test results and decisions about preventive therapy. In 
Cali, Colombia, a study was conducted to assess the risk of TB infection in HIV infected and AIDS patients (Alzate et al. 1993). The studied population included 79 individuals infected with HIV and 48 controls from the trauma unit. They found that when the clinical stage of HIV infection progresses, tuberculin positivity diminishes. In the same study, in the presence of a BCG scar, a tuberculin induration of more than $8 \mathrm{~mm}$ was less frequent in HIV+ individuals compared to controls. Adjusting the tuberculin positivity by presence of BCG scar, the odds ratio for a tuberculin reaction $\geq 8 \mathrm{~mm}$ among $\mathrm{HIV}+$ individuals compared to controls was significantly lower.

It is known that infection with HIV leads to profound changes in numbers of circulating $\mathrm{T} \mathrm{lym}$ phocytes (Larsson et al. 1992, Jones et al. 1993). Most notable, there is an absolute decrease in circulating CD4+ T cells, which is one of the key processes in the development of AIDS, with a significant increase in circulating CD8+ T cells. The levels of CD4+ T lymphocyte decline rapidly in the first 18 months following seroconversion and less rapidly thereafter, while the levels of $\mathrm{CD} 8+$ lymphocytes increase with similar kinetics (Detels et al. 1988, Lang et al. 1989). By contrast, total CD3+ $\mathrm{T}$ lymphocyte counts declined only slightly in the first 18 months following seroconversion and then remain stable. These findings support the hypothesis of a physiological regulation of the number of total circulating T cells, so that the destroyed CD4+ lymphocytes are replaced by newly generated CD4+ and CD8+ lymphocytes (CDC 1990a).

Our findings suggest that in HIV+ individuals the tuberculin skin test is not an accurate method to determine a previous infection by $M$. tuberculosis and hence the initiation of chemoprophilaxis for tuberculosis. We speculate that alterations in the subpopulations of T lymphocytes, mainly the decreased number of CD4+ and the increase in CD8+ cells, may lead to a disbalance in the DTH responses. The positivity of the tuberculin test do not seem to be modified by the BCG vaccination status in HIV+ subjects. These findings emphasize the need of improved tests to detect an infection by mycobacteria in these patients. Detection or quantification of certain antigens or antibodies against mycobacterial antigens that may differentiate the defense response from the vaccinal response or infections by environmental mycobacteria may help to this purpose.

\section{ACKNOWLEDGMENTS}

To the medical personnel and the institutions that allow us to study the patients of the HIV control programs. To Drs Luis F Barrera and Andrés Jaramillo for their critical review of the manuscript.

\section{REFERENCES}

Alzate A, Crespo MP, Carrasquilla G, Corral R, Sánchez N, Muñoz A 1993. Purified protein derivative (PPD) and HIV infection in Cali, Colombia. J AIDS 6: 630-631.

Barnes PF, Le HQ, Davidson PT 1993. Tuberculosis in patients with HIV infection. Med Clin N Am 77: 1369-1390.

Bothamley GH, Beck JS, Potts RC, Grange JM, Kardjito TH, Ivanyi J 1992. Specificity of antibodies and tuberculin response after occupational exposure to tuberculosis. J Infect Dis 166: 182-186.

CDC - Centers for Disease Control 1990a. Screening for tuberculosis and tuberculous infecion in high risk populations: Recommendations of the Advisory Committee for Elimination of Tuberculosis. MMWR 39: 1-7.

CDC - Centers for Disease Control 1990b. Tuberculin reactions in apparently healthy HIV-seropositive and HIV-seronegative women-Uganda. International notes. MMWR 39: 638-646.

CDC - Centers for Disease Control 1991. Purified protein derivative (PPD)-tuberculin anergy and HIV infection: guidelines for anergy testing and management of anergic persons at risk of tuberculosis. MMWR 40(RR-5): 27-33.

Detels R, English P, Girogi JV 1988. Patterns of CD4 ${ }^{+}$ cell changes after HIV-1 infection indicate the existance of a codeterminant of AIDS. J Acquir Immune Defic Syndr 1: 390-395.

Graham NM, Nelson KE, Solomon L, Bonds M, Rizzo RT, Skavotto J, Astemborski JL, Vlahov D 1992. Prevalence of tuberculin positivity and skin test anergy in HIV-1-seropositive and -seronegative intravenous drug users. JAMA 267: 369-373.

Huebner RE, Schein MF, Bass JB 1993. The tuberculin skin test. Clin Infect Dis 17: 968-975.

Jones BE, Young SMM, Antoniskis D, Davidson PT, Kramer F, Barnes PF 1993. Relationship of the manifestations of tuberculosis to CD4 cell counts in patients with human immunodeficiency virus infection. Am Rev Resp Dis 148:1292-1297.

Lang W, Perkins H, Anderson RE, Royce RA, Jewell N, Winkelstein W 1989. Patterns of T lymphocyte changes with human immunodeficiency virus infection: from seroconversion to the development of AIDS. J Acquir Immune Defic Syndr 2: 63-69.

Larsson LO, Magnusson M, Skoogh B-E, Lind A 1992. Sensitivity to sensitins and tuberculin in Swedish children. IV. The influence of BCG vaccination. Eur Respir J 5: 584-586.

Markowitz N, Hansen N, Wilcosky TC, Hopewell PC, Glassroth J, Kvale PA, Mangura BT, Osmond D, Wallace JM, Rosen MJ, Reichman LB 1993. Tuberculin and anergy testing in HIV-seropositive and HIV-seronegative persons. Ann Int Med 119: 185193.

Orme IM, Andersen P, Boom WH 1993. T cell response to Mycobacterium tuberculosis. J Infect Dis 167: 1481-1497

Pesanti EL 1994. The negative tuberculin test. Tuberculin, HIV and Anegry panels. Am J Respir Crit Care 
Med 149: 1699-1709.

Raviglione MC, Narain JP, Kochi A 1992. HIV-associated tuberculosis in developing countries: Clinical features, diagnosis and treatment. Bull WHO 70: 515526.

Rieder HL, Cauthen GM, Kelly GD, Bloch AB, Snider DE 1989. Tuberculosis in the United States. JAMA 262: 385-389.

Sears SD, Fox R, Brookmeyer R, Leavitt R, Polk BF 1987. Delayed hypersensitivity skin testing and anergy in a population of gay men. Clin Immunol
Immunopathol 45: 177-183.

Selwyn PA, Hartel D, Lewis VA 1989. A prospective study of the risk of tuberculosis among intravenous drug users with human immunodeficiency virus infection. N Eng J Med 320: 545-550.

Yamagami M, Lum LG 1992. Bone Marrow Transplantation, p. 187-190. In NR Rose, E Conway de Macario, JL Fahey, H Friedman, GM Penn (eds) Manual of Clinical Laboratory Immunology. 4th Ed., American Society for Microbiology, Washington D.C. 